\title{
Teachers Competency in the Teaching and Learning of Chemistry Practical
}

\author{
Dr. Jimmi Copriady \\ Faculty of Education, University of Riau, Pekanbaru, Indonesia \\ email:jimmiputra30@gmail.com
}

\section{Doi:10.5901/mjss.2014.v5n8p312}

\begin{abstract}
This study aims to explore the contribution of teachers' competency in teaching and learning practical chemistry from the interrelated aspects of designing, planning, implementing and evaluating practical training or experiment in improving the quality and standards of teaching and learning practical chemistry. This is a survey using a questionnaire as the main instrument to determine the four aspects of the aforementioned competencies. The samples are randomly selected consisting of 234 chemistry teachers in Riau, Indonesia. Data were analyzed using multiple regression to assess the contribution of the four components of competency to analyze the quality of teaching and learning for practical chemistry. The findings show that the level of competency in all aspects of designing, planning, implementing and evaluating of practical training is at the moderate level. Solid and strategic efforts need to be taken to increase teachers' competency and acquisition of more sophisticated laboratory materials should be done. Teachers' creativity and initiative in making practical science to be more meaningful will be discussed in this paper.
\end{abstract}

Keywords: Teachers' Competency, Preparing, Planning, Implementation, Evaluation, Practical

\section{Introduction}

Teachers' competency in teaching and learning is an important factor in determining the success of a teaching session. Their ability and wisdom in handling learning activities will have a direct impact on students' active involvement in learning activities. Therefore, the development of teachers competency involving the efforts of fostering positive attitudes (Awang, Jindal-Snape \& Barber, 2013) was a major agenda to strengthen the teaching profession and to ensure great development of the education quality in many countries around the world. In the Indonesian context, the government has set specific standards in determining the implementation of quality education in accordance with the education laws which related to education curriculum, competency of teachers, educational infrastructure, organization of learning activities and educational assessment. Everything is interconnected in assuring the standard of quality. To this regard, particular attention is given on the quality of science subjects in order to create a scientific-minded citizen.

Science subject is covering general science and pure Science of Biology, Physics and Chemistry subjects. Science subjects require practical training as well as theoretical studies. Therefore, to be competent, teachers need to be efficient in designing, planning and implementing the lesson. A part from that, teachers need to assess the practical training and laboratory experiment. The country needs more scientific-minded people to accomplish the national mission for Indonesia to be a developed nation. Therefore, students need to be nurtured to love science and to positively practice scientific culture. According to Kamisah, Zanaton and Lilia (2007) positive attitudes towards science and scientific activities will exist through constant monitoring of experiments and continuous assessment of practical activities. Hence, this study is to determine on how teachers use their competencies to carry out the teaching and learning process, as well as assessment of the chemistry experiments at the laboratory.

\section{Background of the Study}

Science education is the main agenda of the Indonesian Ministry of Education. It is part of the country's mission towards developing a scientific and progressive society. In accordance with the goals of the National Education System in providing quality education, hence it is the responsibility of teachers to have a comprehensive plan, to implement and evaluate every subject. In the context of globalization and industrial world today, knowledge and understanding of the scientific aspects can enhance Indonesians to be more competitive in the global arena.

Various efforts were made at the school level to increase students' interest and competency in science. Special attention is given particularly on teachers' efficiency in providing meaningful experiences for students while exploring the 
science subject. Widyatiningtyas (2010) admits that the process of learning science needs to focus on providing real experience for students to gain a greater understanding of the environment.

One of the ways to improve teachers' competency especially in chemistry is the teachers need to be well versed with the content of the Chemistry curriculum, skillful in using a variety of teaching methods and teaching aids, efficient in coordinating all the necessary equipment and ensure safety of students while conductiong laboratory experiments.

Students are unable to conduct experiments and predict the outcome because they are not accustomed to the laboratory activities. During laboratory activities, students should be given the opportunity to ask questions, make hypotheses, experiments and deduce experimental results through observation, data processing and making inferences (McDermott et al, 1997).

The instruments and apparatus needed for an experiment should be ready before the actual lesson. Data, information or test results on students performance will be taken as the basis for chemistry performance for future students (Popham, 1999). Preparation involves pre perception of an activity to create interesting learning experiences that arouse students interest for a successful learning process (Mulyati Arifin, 1995).

In addition to preparing and conducting the learning process, assessment is the process of collecting data to determine the achievement of educational goals. Sudijono (1996) defines learning assessment as a process or an activity to get a feedback to determine a progression. This is in line with Djamarah (2006) which says that the function of evaluation or assessment is to provide feedback to the teacher in order to improve the learning process and implement remedial programs for unsuccessful students until they are able to improve their own performance.

According to Popham (1998), the capacity and efficiency of teachers in conducting the activity and learning process will have a positive impact on students learning orientation. Teachers are also required to provide authentic learning experiences and create active learning through active interaction with the subject matter. Therefore, teachers need be really competent in their subjects. For chemistry subject, teacher's competency in creating and planning will greatly provide significant impact on the teaching process and will greatly influence students to change their behaviours.

\section{Competency of the Chemistry Teachers}

Competency refers to the skills and personality of a teacher in handling the instructional process with the help of instructional methods, teaching aids and resource. According to Katane and Selvi (2006), competency is "a set of knowledge, skills and proficiency in creating a meaningful experience when organizing an activity".

As a professional, a teacher needs to plan and implement the learning process, evaluate the learning outcomes, provide guidance and training, conduct a research, develop and managing school programs and professional competency. (Competency Standard Of Novice Teachers Graduated From Chemistry Education Course SI 2004).

Therefore, the teachers must have professional educational ability. Competency in this study is referred to the four components of the Chemistry teacher competencies: preparing and designing an experiment, hands-on pratical or experiment plan, implementing and evaluating a systematic and effective experiment. See the following figure.

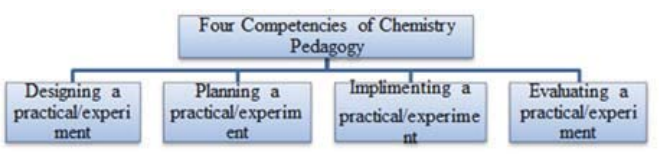

Figure 1: Four Competencies of Chemistry Pedagogy

Katane \& Kiymet Selvi (2006) put forward the definition of competency. It is defined as "a set of knowledge and skills needed to perform an activity". A teacher must have a professional educational competency to conduct the teaching and learning process. Science is knowledge about natural phenomena that involves research and discovery through hands-on practical and laboratory experiments which should be performed under teachers' guidance. Therefore, a competent and professional chemistry teacher will definately understand on how to guide students in performing experiments and practical implementation (Widyatiningtyas 2010).

\section{Problem Statement}

Truth in science can only be proven through practical or experiments. However, students involvement was still low in conducting experiments and they are not effectively guided by the teacher. So they are not given their 100\% interest and 
attention in the laboratory resulting poor outcomes and inability to obtain the actual result of the experiments (Kellough, 1996).

The study shows that teachers are still inefficient in handling laboratory equipment and could not manage a systematic and effective experiment. This might be due to the fact that they fail to plan and the lesson is not organized and structured effectively (Wruheran Sinnadurai, Alyas \& Rohani Abdul Hamid Mohamed, 2004).

Effective teaching occurs when teachers have the knowledge and personality. It is because the science concept is proven through observation and analysis of experiment in the science laboratory. Unfortunately, Chemistry teachers still have a low competency level in conducting practical or scientific experiments. There are mechanical and electrical risks in conducting chemistry experiments, it is also related to students' thinking process when conducting a research. Thus, in reality, teachers do not give the chance for students to think, in fact most teachers misregard students' thinking activities.

Based on the study conducted on high school (SMA) Chemistry teachers in Riau, 45\% of Chemistry teachers do not evaluate the practical experiment objectively in accordance with the actual situation. This leads to inaccurate and invalid experiment results (Jimmi, 2005). Consequently, incompetent teachers significantly influence students' level of interest in the subject.

According to Chang and Leidermen (1994), most students do not have general or specific ideas about the purpose of the inquiry activities in the laboratory and in many practical activities, they do not know what to do.

Truth in science can only be proven through practical activities, but the failure of teachers to prepare their learning materials, improper planning and inappropriate equipments will give negative implications on the implementation and evaluation of practical experiments. The lesson will be useless and will not have any impact on students' behavioral change (Kellough, 1996). Therefore, this study is to examine the relationship between teachers competency of the Chemistry subjects as the input and the basis for teaching reflection and improvement.

\section{Purpose of the Study}

The purpose of this study is to determine the competency of Chemistry teachers in Riau Indonesia and the contribution on Chemistry practical and laboratory experiments. The aspects studied are in terms of designing, planning, implementation and evaluation of practical or chemistry experiements. The contribution is analyzed as a whole by showing the relationship among the four components studied. Contribution and the competency factors identified are expected to help in improving the quality and standards of teaching and learning Chemistry.

\section{Methodology}

This is a survey using questionnaires as the main instrument of the study. The questionnaire consists of four constructs related to preparing for practical or experiments which comprising of 24 items, practical planning involves 22 items, there are 27 items for practical implementation and 29 items for evaluation. Those items were adapted and reconstructed based on the instruments done by Sampson (2004), Muijs \& Reynolds (2001) and Meehan et al. (2004).

The samples were randomly selected based on the sampling schedule presented by Krejie \& Morgan (1970). There are a total of 474 Chemistry teachers in Riau province, Indonesia and thus, only 236 Chemistry teachers were selected from 11 high schools of the Indonesian Ministry of Education. A pilot study was conducted of the four constructs using Cronbach Alpha analysis, and the result showed a high level between 0.81 to 0.91 which is deemed suitable to be used in the actual study.

\section{Findings and Discussion}

\subsection{Competency in Designing the Chemistry Experiment/Practical}

Teachers competency in designing a practical or chemistry experiment was tested and the finding shows Beta $=.686, \mathrm{t}=$ 2617 , sig $=0: 00<0.05$, and R2 $=.470$. This means that teachers' competency in designing is moderate, as it only contributes $47 \%$ to the planning of Chemistry practical. This situation also illustrates that Chemistry teachers are still unable to prepare and design a robust practical or experiment for the Chemistry lesson. Chemistry teachers should proficient on how to plan better steps. According to Erin \&. Alicia (2009) designing learning instructions, setting goals and structuring teaching steps are important, as well as determining the evaluation aspects to be used in the Q \& A session, exercise, test papers and so on. 
Table 1: Regression analysis of the designing/ preparing components for planning Chemistry laboratory experiment

\begin{tabular}{|c|c|c|c|c|c|c|c|c|}
\hline & Model & B & Standard Error & Beta & $\mathrm{t}$ & Sig. & $\mathrm{R}^{2}$ & $\%$ \\
\hline \multirow[t]{2}{*}{ Practical planning } & 1 Constants & 0.533 & 0.204 & & 2.617 & 0.009 & 0.470 & $47 \%$ \\
\hline & Preparation & .865 & 0.060 & .686 & 14.404 & 0.000 & & \\
\hline \multirow[t]{2}{*}{ Practical assessment } & 1 Constants & 1.190 & 0.217 & & 5.486 & 0.000 & 0.347 & $34.7 \%$ \\
\hline & preparation & 0.712 & 0.064 & .589 & 11.144 & 0.000 & & \\
\hline
\end{tabular}

The findings show that teachers competency in designing Chemistry practical activities for evaluation is Beta $=.589, \mathrm{t}=$ 11144 , sig $=0: 00<0.05$, and R2 $=.347$. This finding means that designing competency is only accounted for $34.7 \%$ of all the practical competency assessment. This illustrates that teachers competency in designing practical activities is at the low level. Teacher's ability to design through a good plan and preparation of what to be done is very important because past research suggested that they have a positive impact on the effectiveness of practical training (Rhoda, Yousuf, Mr \& Ranjha, 2011). This low level of competency should be taken seriously because scientific studies show that the effectiveness of practical science is depending on the ability of teachers to design the practice and plan the objectives (Abraham and Millar, 2008).

These findings describe that teachers competency is average in designing Chemistry laboratory experiment. Whereas, the competency in desigining for practical evaluation is low. This indicates that teachers do not emphasise on designing Chemistry laboratory practical or experiment. Teachers must be able to design and develop experiments to perform better practical in teaching. Techers need to have a complete detail of an experiment preparation covering all of the subject identities, competency standards, learning objectives, learning materials, time allocation, teaching methods, learning activities, assessments and learning resources. Implementation of exercises, practical programs and workshops for Chemistry teachers, were actually documented by the Education Department, Board of Education Quality Assurance (LPMP) and Development and Empowerment Center for Educators (P4TK) to help Science teachers in preparing and designing classroom instructions.

\subsection{Competency in Planning for Chemistry Practical/Experiment}

The results show that teachers competency in planning for Chemistry practice is at the moderate level (46.3\%). Weakness in planning can affect the effectiveness of teaching and learning (Abraham and Millar, 2008). Planning is essential in providing a good experience for students during the scientific experiment, therefore pre-lab planning of providing materials and equipment to be used for teaching and practical activities is very important. This is important to avoid delays and distruption in the teaching and learning process. Normally, the preparation is done with the help of the laboratory technicians or assistants who have the background knowledge in the appropriate field. According to Mokhtar (2007) the laboratory is very complex, so it is better for the teachers to know the content, apparatus and equipments in the lab. According to Fathiah, (2007), a Chemistry teacher should have a high level of proficiency in handling the equipment and installation of apparatus as they are parts of their job scope. If teachers have problems in managing the laboratory equipment, the teachers will also face problems in the teaching and assessing the experiments.

The findings of this study may be influenced by the lack of equipment, apparatus and materials in many laboratories. Although the initial setup is particularly important in preparing for an experiment or scientific practice, but the lack of materials and apparatus undermines the efforts to provide a good Chemistry practical or experiment. Preexperiment preparation and planning will ensure a smooth process, however, without appropriate apparatus and materials the process will be useless. Furthermore, laboratory apparatus is constantly evolving with new technology being introduced all the times. Due to that, not all teachers are able to use and understand the manual, consequently they can not use the apparatus effectively.

Table 2: Contribution of Planning Competency in Practical Implementation

\begin{tabular}{|c|c|c|c|c|c|c|c|c|}
\hline & Model & $B$ & standard error & Beta & $t$ & Sig. & $\mathrm{R}^{2}$ & $\%$ \\
\hline \multirow{2}{*}{ Conducting a practical/experiment } & 1 Constant & 1.856 & .112 & & 16.527 & .000 & 46.3 & $46.3 \%$ \\
\hline & preparation & .456 & .032 & .680 & 14.199 & & & \\
\hline Practical evaluation & \begin{tabular}{|ll}
1 & Constant \\
& planning
\end{tabular} & $\begin{array}{c}1.459 \\
.618\end{array}$ & $\begin{array}{l}.168 \\
.048\end{array}$ & .644 & $\begin{array}{l}8.699 \\
12.871\end{array}$ & $\begin{array}{l}.000 \\
.000\end{array}$ & .414 & $41.4 \%$ \\
\hline
\end{tabular}


This study also shows the contribution of competency in planning a practical evaluation, however the contribution is low at $41.4 \%$. Laboratory management has certain effect on the evaluation process. This is because all aspects of the laboratory experiments and practices will be evaluated and tested during the evaluation process to assess the knowledge, ability and thinking ability of the students. Hence, incomplete experimental apparatus will obviously has negative influence in the effectiveness of its assessment. Competent Chemistry teachers are able to clearly explain the procedure for the students to conduct the real experiments. Bryan (2003) found that teachers who are competent in ensuring students to conduct the necessary experiment steps without mistakes will make the practical effective.

It can be deduced that teachers competency is low in preparing the apparatus and materials and incomplete infrastructure for the practical needs. However, the high Schools (SMA) in Riau Province still need to carry out effective Chemistry practical and experiment to implement the curriculum. Therefore it is suggested that experienced teachers can train and teach the novice teachers on the important skills, especially in preparing the apparatus and materials needed for practical activities.

\subsection{Competency in Implementing Chemistry Practical}

The results show that the competency for practical implementation as predictor provides Beta $=.700, t=14986$, sig $=$ $0: 00<0.05, \mathrm{R} 2=.490$ and showing competency contribution of $49 \%$ towards the implementation of practical evaluation. This suggests that the competency to execute a practical experiment is at the moderate level. However, the results show improvement in terms of Chemistry practical evaluation competency (55.3\%) on the practical implementation. This finding clearly indicates that proper preparation and systematic pre-lab planning in managing the laboratory equipment have a very positive impact on the practical implementation of the process itself. According to Weintein (1996) good execution will produce good results in the evaluation process. This opinion is proven by the findings, namely the implementation of good Chemistry teaching will produce a good result and outcomes. Whereas, Nurzatulshima, (2008) has listed several elements of physical environment as important in providing effective learning experiences thereby provide positive impact on the evaluation process. In terms of teaching pedagogy, the lesson will be fun and interesting if the teachers have the ability to attract students through organized and structured experiments.

Table 3: Contribution of Implementation Competency towards Practical Assessment

\begin{tabular}{l|lccccccc}
\hline \multicolumn{2}{l}{ Model } & B & Standard error & Beta & T & Sig. & $\mathbf{R}^{2}$ & $\%$ \\
\hline \multirow{3}{*}{ Practical impelemtation } & Constant & 0.226 & 0.225 & & 1.002 & 0.317 & 0.490 & $49 \%$ \\
& Practical execution & 0.977 & 0.065 & 0.700 & 14.986 & 0.000 & & \\
\hline \multirow{3}{*}{ Practical assessment } & Constant & 1.338 & 0.128 & & 10.489 & 0.000 & 0.553 & $55.3 \%$ \\
& Practical Design & 0.348 & 0.051 & 0.412 & 6.843 & 0.000 & & \\
& Practical Preparation & 0.267 & 0.040 & 0.398 & 6.613 & 0.000 & & \\
\hline
\end{tabular}

The findings of this study reinforce the principles of practical effectiveness which covering the aspects of planned and systematic operation (Abraham and Millar, 2008). Practical or scientific experiment is a process of inquiry research, observation and analysing experimental results. The results show that those three activities in practical or science experiment require the teacher to walk around the groups of students and provide information about the materials and methods to be used in conducting the experiment in the laboratory. In addition, students should also be able to perform Chemistry experiments consistently and continuously using a Student Activity Sheet (LKS).

The findings of this study may also be associated with teachers' attitudes towards teaching and learning (Awang, Ahmad, Wahab \& Mamat, 2013). Effective practical implementation is determined by teachers' ability in guiding students to perform the experiment and students' ability to translate scientific knowledge in practical until there is a balance between the teacher as mentor and students as the learning subjects. According to Hofstein and Lunetta (2003), inquiry or question and answer session in the laboratory is not effective to deliver scientific knowledge and to develop students' scientific skills.

McLeod et al (2003) state that early planning to manage the apparatus and materials is very important. It is good if the teacher has a list of things needed to be given to a group of students. Each group needs to get the right apparatus and materials according to the practical content. This study also shows that self management is one of teachers' shortcomings. Hardin (2004) and Nurzatulshima (2008) have listed five areas that need to be managed well by teachers to improve their lesson. The areas are the management of material and space, setting of rules and regulations, commitments and students' responsibility, discipline and clear instructions. 


\subsection{Competency of Evaluating Chemistry Practical}

The results show the contribution of designing and planning competencies towards practical implementation (53.7\%) are higher than the practical evaluation (45.6\%). This shows that there is a significant relevance among determination of the subject matter, purpose and learning experiences. Apart from that, there is also a significant relation with teacher preparation of laboratory equipment and documentation through practical forms and worksheets. Execution of authentic learning experience through pedagogical skills will increase the validity of practical evaluation to assess students' behavior. Indeed, teachers' knowledge in identifying the purpose and goals of learning, teaching and restructuring pre-lab setup will ensure the evaluation process of practical experiment can be done objectively and will be easily understood by students.

Table 4: Overall Contribution of Teachers' Competencies towards Practical Evaluation

\begin{tabular}{llccccccc}
\hline & Model & B & standard error & Beta & T & Sig. & $\mathbf{R}^{2}$ & $\%$ \\
\hline Practical execution & Constant & 0.142 & 0.226 & & 0.630 & 0.529 & 0.537 & $53.7 \%$ \\
& Practical design & 0.124 & 0.081 & 0.103 & 1.526 & 0.129 & & \\
& Practical planning & 0.272 & 0.064 & 0.283 & 4.237 & 0.000 & & \\
& Practical implementation & 0.610 & 0.096 & 0.426 & 6.382 & 0.000 & & \\
\hline Practical evaluation & Constant & 0.958 & 0.201 & & 4.760 & 0.000 & 0.456 & $45.6 \%$ \\
& Practical design & 0.337 & 0.080 & 0.278 & 4.190 & 0.000 & & \\
& Practical preparation & 0.435 & 0.064 & 0.453 & 6.824 & 0.000 & & \\
\hline
\end{tabular}

The findings of this study indicate that not all teachers are able to provide detail documents of an evaluation. This is an indicator for the teacher training system to formulate a rapid strategic planning to enhance the learning process in order to improve the quality of Chemistry practical. There are standard documenting procedures related to the practical implementation such as the attendance list, student evaluation forms and Student Activity Worksheets (SAW). However, the results show that teachers are incapable to document and keep a good record. According to Mohammad (2007), documenting and keeping a record of documents are very important. Another things that need to be documented are a list of equipment, materials and apparatus needed to be used for every practical and scientific experiments. Other than that, it is important to have practical procedures for a systematic practice based on a specified time frame.

Huey and Lederman (1994) emphasize the need for a clear explanation and instructions before performing an activity. If the teacher fails in explaining the content, students will not be able to understand of what to do and resulting failure in the practical implementation and jeopardizing safety in the laboratory. The teacher needs to be well-versed and knowledgeable of the experiment before the students can conduct their own experiments according to the procedure themselves. A study by Hamman et al. (2000) found that most science classroom approaches are teacher centered. In a study by Rosinah (2005) has found a similar finding. Students are not engage in inquiry activity and the implementation of this approach has not even reached the satisfactrory level. This shows that teachers' instructions and lesson control need to be delivered clearly to ensure the experiment or practical training will be carried out smoothly.

\section{Implications and Recommendations}

In overall, teachers'competencies in planning, designing, implementing and evaluationg are at the moderate level. This has a significant impact on the current system and the process of teacher training. A strategic and comprehensive step needs to be done for the benefits of teachers and for them to be able to handle the Chemistry practical or experiments effectively. The rapid development of global science should be followed closely by the government plans to improve the quality of Chemistry teachers. Recognizing the resource constraints in the provision of equipment and chemical apparatus, a combine effort of the economic development elements for the development of science in schools needs to be done. Due to limitations of the state resources, teachers need to use their own creativity and initiative in dealing with practical Chemistry. Teachers should take the initiative to cleverly use the existing resources in the school environment and surrounding to make Chemistry practical and experiments authentic with human life. Thus, teachers can also reduce the need to rely on advanced equipment and at the same time are still able to attract students. Teachers have a greater role in the scientific practice. An effective teacher should be able to give a step by step instruction especially for inactive students, who just wait for the teacher to guide them in performing the experiment or chemistry practical. Teachers are 
the best source of knowledge and facilitators to facilitate the performance of each group of students. The implication of this study is most teachers fail in facilitating the students especially in handling a large group of students.

\section{Conclusion}

Teacher competency is the pillar for practical implementation of a safe and effective science experiment. Students' positive attitude towards Chemistry and their motivation to learn and provide appropriate feedback to the learning activities is significantly depending on how teachers influenced them. On the other hand, teachers need to have a high capability and competencies in developing laboratory instructions, lesson planning, preparing and documenting laboratory equipment, implementing and translating the process in the form of continuous assessment throughout the teaching practice in the laboratory. A concerted effort is urgently needed to develop the competencies, getting resources and practical equipments for the objective of realizing a science literate society.

\section{References}

Abraham, I. \& Millar, R. (2008). Does Practical Work Really Work? A study of the effectiveness of practical work as a teaching and learning method in school science. International Journal of Science Education. 30(14). 1945-1969

Awang, M.M, Ahmad, A.R., Wahab, J.L.A. \& Mamat, N. (2013). Effective teaching strategies to encourage learning behaviour. IOSR Journal. 8 (2). $35-40$

Awang, M.M., Jindal-Snape, D. \& Barber, T. (2013). A documentary analysis of the government's circulars on positive behaviour enhancement strategies. Asian Social Science. 9(5). 203-208

Bryan, 2003. Nestedness of beliefs: Examining a prospective elementary teacher's: Essential research for lasting reform. Journal of research in science teaching 38 (6): 631-645.

Carter, C.S. \& Brichhouse, N.W. 1989. What Make Chemistry Difficult? Journal of Chemical Education, 66(3): 223-225.

Chang, H.P. \& Lederman, N.G. 1994. The Effect of levels of cooperation with physical science achievement. Journal of Research in Science Teaching, $32,167-181$.

Djamarah, 2006. Learning Performance and Teachers Competency, Surabaya: Usaha Nasional.

Erin \&. Alicia, 2010. The Role of Content in Inquiry-Based Elementary Science Lessons: an Analysis of teacher Beliefs and Enact. Journal of the Australasian Science Education Research Association. Volume 40/3 May 2010.

Fathiah, 2007. Manipulative Skills Mastery Levels Among Chemistry Teacher Trainees. Thesis Education Faculty of Malaysia Technology University.

Hardin, 2004. Effective classroom management. Upper Saddler 5-12. 3rd. Ed. London: Paul Chapman Publishing Ltd.

Hofstein \& Lunetta, 2003. The laboratory in science education: Foundation for 21 $1^{\text {st }}$ Century. Science Education. 88(1): 28-54.

Huey \& Lederman, 1994. The effect of levels of cooperation with physical science laboratory groups on physical science achievement. Journal of Research in Science Teaching, 31 (2): 167-171.

Hamman et al. 2000. Teachers coaching of learning and its relation to student's strategic learning. Journal of Educational Psychology 92 (2) : $342-348$

Kamisah, Zanaton and Lilia, 2007. Attitudes Towards Science and Scientific Attitudes among Science Students.. Journal of education, Malaysia National University, Volume 32.

Katane \& Selvi, 2006. Teacher competence and further education as priorities for sustainable development of rural school in Latvia. Journal of Teacher Education and Training. 6. 2006:41-59.

Kellough, 1996. Integrating Mathematics and Science For Intermediate and Middle School Students. Englewood Cliffs: N.J. A. Simon and Schuster Company.

Krejie \& Morgan, 1970. Determining Sample Size fo Research Activities" Educational and Psychological Measurement. Vol. 30: 607-610.

McLeod et al, 2003. The Key Elements of Classroom Management: Managing Time and Space, Student Behavior and Instructional Strategies. Alexandria VA: ASCD

McDermott et al, 1997. A Physics by Inquiry. Volume I. New York: John Wiley \& Sons, Inc.

Mulyati Arifin, 1995. Development of Chemistry Teaching Program. Surabaya: Airlingga University Press

Muijs \& Reynolds, 2001. Effective Teaching: Evidence and Practice. London: Paul Chapman Publishing.

Meehan et al., 2004. Special strategies observations system-revised: A useful tool for educational research \& evaluation. Baltimore, MD: John Hopkins University.

Mokhtar, 2007. Work Problems of Science: The Effects on Safety Awareness and Practise in the Science Laboratory. Thesis for Education Faculty Malaysia National University.

Mohammad, 2007. KTSP, Management of Implimentation and School Readiness. Yogyakarta: Pustaka Pelajar

Nurzatulshima, 2008. Management of Students' Involvement in Practical Science. Malaysia Education Journal. 34 (1): 205-2017.

Popham, 1998. Classroom assessment: What teachers need to know. Needham Heights, MA : Allyn and Bacon.

Rosinah, 2005. Implimentation of Inquiry-Discovery Approach in Science Education. Doctorate Thesis. Malaysia National University.

Rhoda D.B., Yousuf, M.I, Awang, M.M., Ranjha, A.N., (2011). The effect of prior

knowledge in understanding chemistry concepts by senior secondary school students. International Journal of Academic Research. 3(2), 607-611

Sudijono, 1996. Introduction to Educational Statistics. Jakarta : Rajawali.

Sampson, 2004. The Science management observation protocol. Dalam The Science Teacher. 71 (10): 30-33

Widyatiningtyas, 2010. Teachers' Role in Skills Asessment Process. http://educare.efkipunla.net/index2.php?option=com_content\&do_pdf=1\&id=49

Wruheran Sinnadurai, Alyas Mohamed \& Rohani Abd Hamid, 2004. Science Practical In Teaching and Learning Science Subject among Form Four Students. Department of Science. Kuala Terengganu Teaching College (online) http://mpt.edu.my/penyelidikan/ amalisains.htm. [4 Februari 2004].

Weintein, 1996. The Teaching of Learning Strategies. N Wtrock, M.C. (Ed.) Handbook of Research on Teaching. New York: McMillan. 